\title{
Desigualdade de gênero e Covid-19: os reflexos da pandema na vida das mulheres
}

\author{
Desigualdad de género y Covid-19: los reflejos de la pandemia en la vida de las \\ mujeres
}

\section{Luíza Souto Nogueira ${ }^{\mathbf{1}}$}

Universidad de São Paulo, Brasil

Mariana Orsini Simonetti Di Gregorio ${ }^{2}$

Escola Superior do Ministério Público de São Paulo, Brasil

\begin{abstract}
RESUMO O objetivo do presente trabalho é, a partir de revisão bibliográfica somada à análise de dados, identificar em que medida a pandemia de COVID-19 agravou a desigualdade de gênero vivenciada pelas mulheres. Para tanto foram analisados os conceitos de gênero e desigualdade de gênero, bem como os impactos por ela experimentados em decorrência da decretação de medidas para o combate à pandemia causada pelo coronavírus, especialmente o isolamento social imposto pela quarentena. Dentre as inúmeras consequências possíveis, concentrou-se a pesquisa em analisar os impactos vivenciados no ambiente doméstico e familiar, o que permitiu perceber que a pandemia de COVID-19 implicou um aumento das atividades delegadas às mulheres em razão da desigualdade de gênero, bem como elevou os índices de violência doméstica.
\end{abstract}

PALAVRAS-CHAVE Mulher; gênero; desigualdade; pandemia; COVID-19.

1. Doutoranda em Direito Civil pela Faculdade de Direito da Universidade de São Paulo (USP), Mestre em Direito Civil pela Pontifícia Universidade Católica de São Paulo (PUC/SP) e Especialista em Interesses Difusos e Coletivos pela Escola Superior do Ministério Público de São Paulo. Mail: luizasnogueira@yahoo.com.br.

2. Especialista em Interesses Difusos e Coletivos pela Escola Superior do Ministério Público de São Paulo. Mail: mosimonetti18@hotmail.com. 
RESUMEN El objetivo del presente trabajo es, a partir de una revisión bibliográfica agregada al análisis de datos, identificar en qué medida la pandemia COVID-19 ha agravado la desigualdad de género que viven las mujeres. Para ello, se analizaron los conceptos de género y desigualdad de género, así como los impactos que ellas experimentaran como consecuencia de la promulgación de medidas para combatir la pandemia provocada por el coronavirus, especialmente el aislamiento social impuesto por la cuarentena. Entre las múltiples consecuencias posibles, la investigación se concentró en analizar los impactos vividos en el ámbito doméstico y familiar, lo que permitió darnos cuenta de que la pandemia de COVID-19 implicó un aumento de las actividades delegadas a las mujeres por la desigualdad de género, así como elevó las tasas de violencia doméstica.

PALABRAS CLAVE Mujer; género; desigualdad; pandemia; COVID-19.

\section{Introdução}

Este trabalho tem como tema a desigualdade de gênero e os impactos da pandemia de COVID-19 na vida das mulheres e, como objeto, quais as consequências vivenciadas pelas mulheres em seu dia a dia em decorrência da situação causada pelas medidas de prevenção à contaminação pela doença causada pelo coronavírus.

O problema de pesquisa que embasou o presente artigo fundamentou-se nas seguintes questões, a saber: de que forma as medidas de isolamento social refletem na vida das mulheres? É possível dizer que mulheres têm a situação decorrente da desigualdade de gênero agravada neste momento de pandemia?

A condição jurídica da mulher no âmbito das relações sociais ainda não é de igualdade plena em relação aos homens, o que se deve à presença da ideologia de gênero na sociedade, situação que se agrava quando, em decorrência da pandemia de COVID-19, as pessoas passam a ficar a maior parte do tempo dentro de casa, nele tendo que conciliar as atividades domésticas com as profissionais.

Justamente por isso o objetivo do presente trabalho foi realizar um estudo sobre como a desigualdade já vivenciada pelas mulheres se agravou no cenário causado pelo coronavírus. Para isso foram analisados os conceitos de gênero e desigualdade de gênero, bem como os dados que demonstram a maior suscetibilidade das mulheres a ela no cenário atualmente vivenciado.

Por meio do método hipotético-dedutivo realizou-se pesquisa de natureza bibliográfica, com revisão sistemática da doutrina acerca das temáticas de gênero e das mulheres, com o objetivo de sintetizar seus resultados e conclusões. 
E com o uso do método comparativo, por meio da análise de dados, buscou-se identificar qual é o impacto causado pela COVID-19 na vida das mulheres.

\section{O que é desigualdade de gênero}

Entende-se que a existência dos sexos feminino e masculino se deve a uma série de características biológicas e fisiológicas que se definem no momento da formação da vida humana, formando diferenças que dizem respeito ao funcionamento do corpo humano. Sexo é, portanto, o conceito construindo ${ }^{3}$ tendo em vista diferença fisiológica decorrente da anatomia humana ${ }^{4}$.

Ocorre que, ao longo dos anos, a sociedade se organizou de maneira a dividir os papéis a serem exercidos por homens e mulheres, consagrando diferenças de tratamento entre eles tão somente em razão de pertencerem ao sexo identificado como masculino ou feminino. É aqui que surge a noção de gênero ${ }^{5}$, que não se confunde com a de $\operatorname{sexo}^{6}$.

O gênero é, portanto, uma construção social7; é o conjunto de características atribuídas a homens e mulheres tendo em vista as diferenças biológicas entre eles existentes $^{8}$. E, por ser construção social, encontra variações nas diferentes sociedades.

O Decreto 8.727/2016 estabelece em seu artigo $1^{\circ}$, parágrafo único, inciso II, que por identidade de gênero deve-se compreender a "dimensão da identidade de uma pessoa que diz respeito à forma como se relaciona com as representações de masculinidade e feminilidade e como isso se traduz em sua prática social, sem guardar relação necessária com o sexo atribuído no nascimento”.

O grupo HERA (Health, Empowerment, Rights and Accountability) conceitua gênero como o conjunto de relações, atributos, papéis, crenças e atitudes que definem o que é ser um homem ou uma mulher na sociedade, que não são determinados pelo sexo biológico, mas por uma construção histórico-social passível de transformação9.

E continua explicando que em muitas sociedades as relações de gênero são desiguais, o que reflete nas leis, políticas e práticas sociais, bem como no comportamento da sociedade. Destaca, ainda, que essa desigualdade tende a agravar outras existentes na sociedade, como de classe, raça, orientação sexual, deficiência ${ }^{10}$ :

3. CECCARELLI (2010) p. 272.

4. SHAPIRO (1981) p. 449.

5. LAMAS (1994).

6. GURGEL (2019) p. 428.

7. BUTLER (2003) p. 24.

8. MELERO AGUILAR (2016) p. 76.

9. HERA (1998) p. 18.

10. Idem. 
Percebe-se, portanto, que os conceitos de gênero feminino e masculino nada mais são do que construções sociais com base nos comportamentos esperados das pessoas conforme o sexo biológico que nasceram.

E da diferenciação de papéis programados pela sociedade para homens e mulheres emerge a disparidade de tratamento nas mais variadas áreas da sociedade, colocando a mulher, em todas elas, em posição desvantajosa em detrimento do homem, cuja função social sempre foi vista como de maior importância, força e poder, como destaca Silvia Chakian ${ }^{11}$.

A título de exemplo pode-se verificar a legislação sobre Direito de Família, que, no Código Civil de 1916 foi editada (por homens) sob a inspiração da ideia de superioridade e dominação do homem sobre a mulher, como ensina Maria Berenice Dias ${ }^{12}$.

E por ser a desigualdade a regra, as normas de cunho penal também acabaram por consagrar desigualdades no âmbito da tutela merecida por homens e mulheres.

Até a edição do Código Penal do Império, em 1830, estava o homem autorizado a matar a mulher adúltera. Após a entrada em vigor deste diploma tal autorização foi suprimida. Entretanto, o adultério continuou a ser tratado de maneira diferente conforme o gênero daquele que viesse a incorrer nesse crime.

Verifica-se que a mulher que cometesse adultério estaria sujeita a prisão, ao passo que o homem somente seria punido com essas penas caso tivesse concubina, teúda, e manteúda, ou seja, exigia-se uma relação habitual fora do casamento, com vínculo de dependência econômica; meras relações sexuais esporádicas não configuravam adultério.

No que tange à tutela da liberdade sexual, à época, a punição para crimes sexuais era mais rigorosa caso as vítimas fossem mulheres virgens ou honestas, havendo previsão expressa de pena menor caso a estuprada fosse prostituta ${ }^{13}$.

Esse cenário de diferenças de papéis entre homens e mulheres, bem como de diferenças entre mulheres a justificar a aplicação de penas mais brandas para aquelas que viessem a ser vítimas de violência sexual, mas não ocupassem o status de virgem ou honesta, acabou por propiciar a normalização de uma cultura de violência contra a mulher.

11. CHAKIAN (2019) p. 49

12. DIAS (2015) p. 101.

13. Art. 219. Deflorar mulher virgem, menor de dezasete annos. Penas - de desterro para fóra da comarca, em que residir a deflorada, por um a tres annos, e de dotar a esta. Seguindo-se o casamento, não terão lugar as penas. Art. 222. Ter copula carnal por meio de violencia, ou ameaças, com qualquer mulher honesta. Penas - de prisão por tres a doze annos, e de dotar a offendida. Se a violentada fôr prostituta. Penas - de prisão por um mez a dous annos. 
Violência essa que ora se justificava pelo fato de ser ela vista como naturalmente inferior, de valor social menor; ora pela crença de não ser ela digna de proteção por dedicar-se à prostituição ou simplesmente por ter perdido o "selo social" de mulher honesta ${ }^{14}$.

Ocorre que ainda não conseguimos superar as barreiras socioculturais que impedem a adoção de tratamentos efetivamente igualitários entre homens e mulheres, principalmente em relação a seu papel na sociedade e aos direitos que possuem.

As desigualdades consagradas tão somente em razão do gênero estão presentes em todos os setores sociais e, como se analisará no presente trabalho, se agravam diante de situações como a que está sendo vivenciada no momento: uma pandemia.

O presente trabalho, portanto, pretende realizar uma análise acerca das consequências da pandemia de COVID-19 no dia a dia das mulheres, observando como a existente desigualdade de gênero implica o agravamento das situações por elas vivenciadas, trazendo uma sobrecarga física e emocional raramente experimentada por homens.

\section{Desigualdade de gênero e COVID-19}

No dia 11 de março de 2020 a Organização Mundial da Saúde (OMS) declarou como pandemia a contaminação pelo vírus Sars-Cov-2 ${ }^{15}$, que foi denominado COVID-19 em 11 de fevereiro de $2020^{16}$.

Mas, desde antes de ter sido a contaminação por coronavírus elevada ao status de pandemia, já vigia no Brasil, desde 06 de fevereiro de 2020, a Lei ${ }^{\circ} 13.979$, que dispõe sobre as medidas para enfrentamento da emergência de saúde pública de importância internacional decorrente do coronavírus responsável pelo surto de 2019.

Referida Lei estabelece, em seu artigo $3^{\circ}$, as medidas que podem ser tomadas pelas autoridades públicas para enfrentamento da doença, dentre as quais se destaca a quarentena, definida pelo artigo $2^{\circ}$, II, como a "restrição de atividades ou separação de pessoas suspeitas de contaminação das pessoas que não estejam doentes, ou de bagagens, contêineres, animais, meios de transporte ou mercadorias suspeitos de contaminação, de maneira a evitar a possível contaminação ou a propagação do coronavírus".

A quarentena, portanto, autorizada pela lei em comento, imposta em cada estado brasileiro de acordo com as especificidades locais estabeleceu uma situação que tem sido chamada de isolamento social. Por meio dela, todas as atividades que podem

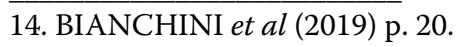

15. UNA-SUS (2020).

16. WORLD HEALTH ORGANIZATION (2020). 
ser exercidas de maneira remota passaram para a modalidade home office e, aquelas não essenciais, tais como comércio e lazer, tiveram seu funcionamento fechado ao público.

Inúmeros são os impactos que essas medidas trouxeram para a vida de todas as pessoas. Dentre eles, pretende-se, aqui, realizar uma análise sobre os que foram vivenciados pelas mulheres.

De acordo com o Inter-Agency Standing Committee (IASC), a partir do momento em que foi declarada a pandemia, reconhecer como ela afeta diferentemente homens e mulheres passou a ser muito importante. Dados preliminares indicam que a taxa de mortalidade é maior entre os homens, o que se dá provavelmente em razão de diferenças imunológicas, altas taxas de doenças cardiovasculares entre homens e estilos de vida. Entretanto, surtos como de Zika e Ebola, bem como a pandemia de AIDS, têm demonstrado que uma análise de gênero robusta e uma resposta informada e integrada ao gênero são vitais para fortalecer o acesso e a aceitação dos serviços humanitários necessários para atender às diferentes necessidades de mulheres e meninas, bem como homens, meninos e pessoas LGBTI. As normas de gênero e as desigualdades preexistentes impactam desproporcionalmente mulheres e meninas em emergências, incluindo emergências de saúde. $O$ gênero, juntamente com outros fatores, incluindo idade, orientação sexual e identidade de gênero, etnia, deficiência, educação, emprego e localização geográfica, podem se cruzar para formar experiências individuais ainda mais complexas em emergências ${ }^{17}$.

Justamente por isso, o IASC destacou uma série de impactos de gênero que emergiram em decorrência da pandemia de COVID-19, tais como: mulheres têm maior probabilidade de atuar na linha de frente, seja trabalhando na área da saúde, seja na parte de limpeza hospitalar, razão pela qual possuem maior probabilidade de se contaminar; mulheres podem ter acesso limitado às informações adequadas, o que pode aumentar o risco de contaminação; em muitos lugares as mulheres são as principais responsáveis pelo ambiente doméstico, razão pela qual é possível que tenham que abandonar seus empregos para tomar conta das crianças ou de familiares, o que impacta as suas finanças e aumenta sua exposição ao vírus; as mulheres têm maior probabilidade se aceitar trabalhos com benefícios precários e, em razão disso aceitar situações que impliquem em abuso/exploração sexual; mulheres e meninas terão mais dificuldade de acessar serviços de saúde, o que aumenta a taxa de mortalidade relacionada à gestação; em razão da necessidade de realizar pré-natal, mulheres grávidas ficam mais expostas ao vírus, assim como mulheres mais velhas que continuam acessando o sistema de saúde; interrupções na cadeia de suprimentos e a lotação do sistema de saúde podem levar a um aumento de gestações indesejadas, e consequen-

17. IASC (2020). 
temente, de mortalidade gestacional; o isolamento e as restrições de locomoção podem fazer com que mulheres e meninas fiquem em intenso convívio com seus abusadores; o fechamento de escolas e o distanciamento social impacta meninos e meninas de forma diversa, pois estas terão mais chance de terem que cuidar das responsabilidades domésticas, limitando o tempo de dedicação às atividades escolares remotas; novas formas de abuso, exploração e violência doméstica vão surgir, e as existentes vão se agravar; mulheres trabalhadoras rurais vão ter maior perda de rendimentos e menor acesso a informações; e as restrições de viagem vão impactar as mulheres trabalhadoras rurais e as imigrantes, que podem acabar sendo mais expostas ao risco de contaminação em razão dos trabalhos que possuem ${ }^{18}$.

Como se pode ver, diversos são os impactos que a pandemia de COVID-19 pode causar na vida das mulheres, impactos que são maiores do que as dificuldades causadas na vida dos homens.

Entretanto, em razão da necessidade de se realizar um recorte metodológico, neste trabalho serão analisados, tão somente, as consequências que o coronavírus trouxe para as mulheres no âmbito das relações familiares (àquelas subjacentes ao núcleo familiar no qual essa mulher está inserida), sociais (a visão da comunidade e a expectativa dessa mulher como centro das atividades laborais domésticas, emocionais) e profissionais.

\subsection{A sobrecarga das mulheres no âmbito doméstico e familiar}

A Constituição Federal em seu artigo $5^{\circ}$, caput, prevê que a igualdade como direito que deve ser garantido a todos: “Todos são iguais perante a lei, sem distinção de qualquer natureza, garantindo-se aos brasileiros e aos estrangeiros residentes no País a inviolabilidade do direito à vida, à liberdade, à igualdade, à segurança e à propriedade $[\ldots] "$.

O preceito constitucional em questão objetiva impedir que a legislação estabeleça critérios que impliquem em desigualdades entre os indivíduos que a ela estão sujeitos. Como destaca Celso Antônio Bandeira de Mello, a lei deve ser "instrumento regulador da vida social que necessita tratar equitativamente todos os cidadãos" ${ }^{19}$.

Nessa linha de pensamento, entende-se por um tratamento igualitário aquele que, observando a medida das diferenças existentes, trate de maneira igual aqueles que são iguais e desigual aqueles que são desiguais. Somente assim será possível atingir um patamar em que todos se encontrarão em posição igualitária.

18. IASC (2020).

19. MELLO (2008) p. 10. 
Ao lado dessa previsão constitucional, o artigo $3^{\circ}$ da Carta Magna, em seu inciso III, estabelece, como um dos objetivos fundamentais da República Federativa do Brasil, "erradicar a pobreza e a marginalização e reduzir as desigualdades sociais e regionais".

Percebe-se que tais previsões constitucionais não se limitam, entretanto, a regular a atuação do legislador. São, porém, preceitos que devem ser observados por todos os ramos do nosso ordenamento, inclusive pelas relações particulares reguladas pelo Direito Civil.

Indiscutível a incidência desse princípio como informador das relações matrimoniais, uma vez que nelas as partes da relação (cônjuges) devem exercer direitos e deveres em nível de igualdade.

A aplicação deste princípio visa muito mais do que garantir que os efeitos advindos do casamento não contrariem os ditames constitucionais.

Trata-se de concretizar constitucional e infraconstitucionalmente a mudança da concepção patriarcal de família para a concepção igualitária e de solidariedade entre os cônjuges, acabando com a ideia antigamente consagrada em nosso ordenamento de que o homem figurava como parte principal e dotada de autoridade no casamento, ao passo que a mulher nada mais era do que uma figura a ele acessória e dependente, que não detinha autonomia para escolher os rumos da família.

Entretanto, em que pese a normatização atual do Direito de Família estar em consenso com a previsão constitucional no sentido de que homens e mulheres são iguais perante a lei, a sociedade e a família, não é essa a realidade de todas as famílias brasileiras.

Infelizmente a legislação não é capaz de mudar o pensamento de toda a sociedade no momento em que uma lei nova entra em vigor. E, com isso, nem sempre as alterações legislativas são aplicadas de maneira efetiva nas relações interpessoais.

É isso o que ocorre nas relações familiares. A lei está de acordo com a necessidade de se estabelecer a igualdade entre homens e mulheres, buscando extirpar a desigualdade de gêneros nas relações familiares. Porém, a existência de previsão legal não tem efeito automático sobre a sociedade.

Ainda são muitos os homens que se portam como se fossem verdadeiros chefes de suas famílias, únicos responsáveis por todas as decisões a serem tomadas nesse contexto. Comportamento esse nem sempre questionado por suas esposas.

Ao mesmo tempo, muitas famílias ainda educam seus filhos sob uma perspectiva machista e patriarcal, ensinando-lhes que deve, sim, haver uma diferença entre homens e mulheres tão somente em razão do gênero. Com isso muitas meninas ainda são criadas para aprender desde cedo os afazeres domésticos, enquanto os meninos para se divertir e desenvolver-se profissionalmente. 
Ainda vige o pensamento de que o feminino é delicado e frágil, com emoções mais afloradas e, em alguns períodos do mês, descompensadas; enquanto o masculino traz, juntamente com suas características biológicas, uma maior racionalidade e força, com aptidão para o trabalho externo e aversão às atividades domésticas.

Com a manutenção desse pensamento na sociedade, a desigualdade de gêneros persiste em suas diversas esferas ${ }^{20}$ : os filhos ainda são tidos por muitos como responsabilidade da mulher, bem como os deveres referentes à manutenção da residência, à alimentação, à economia doméstica.

Como reflexo dessa responsabilização da mulher pela prole pode-se apontar a visão ainda muito comum no Judiciário de que é a mãe naturalmente a melhor pessoa para ficar com a guarda dos filhos em caso de divórcio. E quando há decisão diversa, há uma criminalização coletivo-social de que àquela mulher não merecia ser mãe, visto que sua figura fora substituída pela a do pai, partindo, por vezes, tal julgamento de outra mulher.

Também pode-se mencionar diferença gritante entre as licenças maternidade e paternidade. Enquanto a lei confere à mulher o período de 120 dias, que pode ser de até 180 dias em alguns casos; aos homens são conferidos apenas 5 dias, que poderão ser estendidos para 20 em determinadas situações.

Ainda há muitas famílias que educam seus filhos ensinando-lhes que, por serem homens, eles têm necessidades a suprir (dentre elas, necessidades sexuais) e que sua obrigação para com a família já está completa com o trabalho realizado externamente à residência que garante o sustento da mulher e dos filhos, não havendo qualquer dever de realizar atividades relativas ao âmbito doméstico ${ }^{21}$.

Também no âmbito do Judiciário se percebe, ainda hoje, uma resistência em reconhecer a necessária igualdade entre homens e mulheres frente às questões que são levadas à apreciação do juiz. Como aponta Maria Berenice Dias, em casos de determinação de guarda de filhos analisa-se se a mãe se enquadra no papel social que dela é esperado, desconsiderando outros aspectos mais importantes para a determinação de quem será o detentor da guarda, tais como o afeto e a vontade de assumir esse papel ${ }^{22}$.

Somente em 2015 passou a ser aceito que a mulher, após o divórcio, realize a alteração de seu nome no registro de nascimento dos filhos ${ }^{23}$.

A perpetuação desses ideais machistas e misóginos colabora para a violência sofrida por muitas mulheres no âmbito da família. Violência essa que não se limita às agressões físicas, mas que se exerce também pelas vias psicológica, sexual, patrimonial e moral.

20. FERRAZ y LEITE (2013) pp. 376-377.

21. PIOVESAN (2008) p. 19.

22. DIAS (2015) p. 107.

23. DIAS (2015) p. 108. 
Também colabora para que, a despeito da existência de normas que extirparam as diferenças de gênero, elas ainda estejam presentes em diversos setores da sociedade e, inevitavelmente, em muitas relações familiares.

Todas essas situações acabaram por se agravar no cenário de isolamento social criado para tentar combater a pandemia de COVID-19. Ampliando a situação de desigualdade evidenciada pelas mulheres, é certo que a pandemia causou uma abrupta alteração na vida de todos. Contudo, para as mulheres, ficar em casa com os seus significou não somente uma medida protetiva, em razão da sobrecarga de tarefas domésticas que majoritariamente lhes recai.

Se a mulher já era comumente vista como aquela pessoa naturalmente responsável pelos cuidados no lar, tanto no que se refere aos trabalhos domésticos, quanto no que diz respeito ao cuidado com os membros do núcleo familiar, essa situação ficou ainda mais visível.

Aquelas mulheres que estão inseridas no mercado de trabalho e que, antes do cenário da pandemia, dividiam seu tempo entre sua atividade profissional e o cuidado com o ambiente doméstico, com os filhos e com a atenção requerida pelo seu parceiro, agora passaram a exercer seu of ício dentro de casa. Isso gera, muitas vezes, uma confusão entre a sua real disponibilidade para olhar para as necessidades das pessoas da família. A mulher está dentro de casa, mas ainda possui as mesmas responsabilidades e cobranças profissionais que possuía quando, para trabalhar, saía do ambiente doméstico e se dedicava ao seu of ício.

Aquelas que, por outro lado, já se dedicavam ao cuidado da casa e dos filhos, tiveram o seu trabalho aumentado. As crianças em casa precisam de ajuda para estudar, tendo em vista a necessidade de adaptação ao sistema remoto de ensino que foi rapidamente implantado para suprir o fechamento das escolas. A casa com todo mundo dentro o tempo todo fica mais suja, a louça é maior, a quantidade de comida a ser preparada aumenta. A demanda por atenção psicológica dos filhos e parceiro também aumenta. A situação é de stress emocional e aqueles que dependem da mulher para ajudar nesse momento acabam recorrendo mais ainda a ela.

A quarentena significou, portanto, continuar a exercer o seu of ício agora em um confinamento familiar, tendo que dividir espaço entre trabalho home office, afazeres domésticos redobrados devido a crise sanitária e ampla divulgação de protocolos de higienização pessoal e de lares, locais de trabalho, etc., educação da prole uma vez que instituições de ensino tiveram suas instalações físicas fechadas e, não menos importante, o constante lidar emocional de todos os entes que compõe o seu núcleo familiar, porque essa é a tarefa que socialmente e historicamente foi imposto à mulher: cuidar de tudo e de todos a todo momento. 
Bem, extrai-se que a jornada da mulher se tornou uma jornada tripla de trabalho, ainda mais quando essas não podiam contar com uma rede de apoio familiar que antes detinham, em razão dos riscos de disseminação do COVID-19, e se analisarmos a disparidade social ainda, verificou-se que mulheres de regiões de maior vulnerabilidade social foram compelidas a enfrentar o medo diário de contrair o COVID-19 para proporcionar aos seus a manutenção dos insumos mais basilares de vida.

A situação é ainda mais alarmante e desigual quando analisamos a mulher de extrema vulnerabilidade econômica, negra, que vive de renda informal (por exemplo, exercendo trabalho doméstico do tipo diarista em diversos lares e que foi dispensada devido a crise sanitária provocada pelo novo Coronavírus), desempregada e compelida a trilhar os caminhos da prostituição para prover o básico para seus filhos.

Outra preocupação que sobrecarregou as mulheres em meio a essa pandemia foi concernente aos seus direitos reprodutivos e sexuais. Tais direitos igualmente importantes enfrentaram as adversidades causadas pelo COVID-19, com o aumento do número de internações causadas pela doença, mulheres parturientes tiveram que se ver compelidas a enfrentar o medo e desafios da fase final de uma gestação, arriscando-se em consultas neonatais por vezes remanejadas para centros médicos longes de suas localidades, com uma equipe de saúde distinta da de seu costume, além do risco de contaminação contínuo pelo novo Coronavírus, agravando-lhe a sobrecarga emocional e física que sua própria condição já lhe impôs.

\subsubsection{O problema da violência doméstica}

Campanhas de combate à violência doméstica de mulheres foram amplamente divulgadas por meio de veículos informativos de radiotelevisão, bem como a internet tratou de manter esse tema em debate desde o início das medidas de isolamento social para contenção da disseminação do novo Coronavírus Sars-Cov-2.

O Governo Federal, por meio de seu Ministério da Mulher, da Família e dos Direitos Humanos reiterou a possibilidade de denúncia (mesmo que anonimamente) da situação de violência doméstica vivenciada por uma mulher ${ }^{24}$, movimento esse que ganhou forte cenário no atual pandemia do COVID-19, não bastando o medo da doença e de suas inúmeras consequências e tratamentos ainda sob investigação.

O Instituto Maria da Penha alertou sobre o aumento do número de ocorrências de violência doméstica durante a quarentena ${ }^{25}$.

O Fórum Brasileiro de Segurança Pública (FBSP) apresentou dados alarmantes: entre abril e março de 2020 o número de feminicídios no Brasil foi 22,2\% maior do

24. MINISTÉRIO DA MULHER, DA FAMÍLIA E DOS DIREITOS HUMANOS (2020).

25. INSTITUTO MARIA DA PENHA (2020). 
que o registrado no mesmo período no ano de 2019. Somente no Estado de São Paulo, a Polícia Militar registrou um aumento de 44,9\% do número de atendimentos realizados para mulher vítima de violência, ao mesmo tempo em que diminuíram em 3,7\% as medidas protetivas de urgência concedidas ${ }^{26}$.

A preocupação com o crescimento do número de vítimas da violência em seus lares causou repercussão mundial, o que levou a Organização Mundial da Saúde (OMS) a solicitar em 14 de abril de 2020 que os governos limitassem o consumo de bebidas alcóolicas durante esse período da pandemia e o isolamento social estabelecido pela quarentena, em razão do aumento na probabilidade de gerar mais violência doméstica pelo ingestão da bebida e de consequências mais graves, como o feminicídio ${ }^{27}$.

Esse cenário do aumento da violência contra a mulher não se instalou somente no Brasil: na China o número de casos dobrou durante a quarentena, e países como Chipre, Taiwan, França e Singapura, houve um aumento de 30\%, entre outros países ${ }^{28}$.

Exigiu-se, novamente, um suporte maior das mulheres quanto a crise sanitária vivenciada por todo o planeta. No tocante ao risco do enfrentamento da violência doméstica, as mulheres permaneceram com sua vulnerabilidade em âmbito multifatorial, visto que perderam contato com sua rede de apoio de amigos e familiares, passaram a permanecer a todo momento próximo ao agressor, gerando um constante estado de tensão física, emocional e social. E se não bastasse, a quarentena impôs o desafio de enfrentar um eventual desemprego, a educação escolar dos filhos, os incontáveis afazeres domésticos expandidos pelo COVID-19, uma vez que uma simples ida a um supermercado tornou-se uma tarefa sobrecarregada pela posterior limpeza de todos os itens lá adquiridos, como medida profilática contra o novo Coronavírus.

\subsection{A atuação das mulheres na linha de frente de combate ao coronavírus}

A desigualdade de gênero tomou proporções cada vez mais evidenciadas. Toda a perspectiva que remonta às mulheres, como centro de suas famílias, como geradoras de tranquilidade familiar, agora assumira um papel importante no combate ao COVID-19. O Conselho Federal de Enfermagem informou que 84,7\% de seu quadro de profissionais inscritos são do sexo feminino ${ }^{29}$. Desta forma, dentro desse recorte estatístico, é possível concluir que as mulheres participam com expressão do combate ao novo coronavírus.

26. FORUM BRASILEIRO DE SEGURANÇA PÚBLICA (2020).

27. G1 (2020).

28. AZEVEDO et al. (2020).

29. AZEVEDO et al. (2020). 
E esta cena se repete em outras profissões que compõe o quadro de multiprofissionais da área da saúde. Segundo o Fundo de População das Nações Unidas (UNFPA) houve um aumento das desigualdades de gênero e significativa piora da qualidade de vida das mulheres. Além disso, há predominância das mulheres na força de trabalho da saúde: em nível global, cerca de 70\% das equipes de trabalho em saúde e serviço social são compostas por profissionais do sexo feminino ${ }^{30}{ }^{31}$.

No Brasil essa estatística não é muito diferente. O CONASEMS (Conselho Nacional de Secretarias Municipais de Saúde) divulgou que internamente as mulheres representam 65\% de um total de 6 milhões de profissionais da saúde ocupantes de cargos nas esferas público e privada em nosso país ${ }^{32}$.

As mulheres, consoante todo o exposto, corroboraram diariamente na luta contra o COVID-19. Não somente àquelas profissionais da saúde, que em alguns casos tiveram que sair de seus lares e residir temporariamente em seus locais de trabalho, evitando o risco de disseminação do vírus para os seus familiares, por exemplo, devido a uma escassez global de equipamentos de proteção individual (EPIs) para o adequado combate à doença o que impôs as mulheres uma situação de maior vulnerabilidade, visto que nem sempre esses equipamentos são moldados no físico feminino ${ }^{33}$, como também por razões financeiras como o desemprego do companheiro/companheira, o que lhes acarretou um aumento das despesas familiares, não lhe restando outra alternativa se não o suprimento das necessidades básicas de seu núcleo familiar.

\section{Conclusão}

O papel, portanto, da mulher, frente aos desafios enfrentados por todos na atual pandemia do COVID-19 ganhou maiores contribuições para o controle de interno de seus núcleos familiares, bem como vem colaborando para o controle mundial da doença, seja ocupando postos de trabalho na linhas de frente de combate ao novo coronavírus, seja exercendo suas funções domésticas, profissionais e sociais em seus lares, conforme medida de isolamento social (quarentena) adotada pela maioria dos governos.

De fato, ao tratar do cenário atual, ninguém estava preparado para o enfrentamento do medo, da incerteza e de tantos outros aspectos ligados à crise sanitária que o coronavírus gerou no Brasil. Além de perdas de vidas em escala global, o vírus aflorou crises econômicas, sociais, culturais e acentuou desigualdades de gênero entre

30. HERNANDES y VIEIRA (2020).

31. UNFPA BRASIL (2020).

32. CONSELHO NACIONAL DE SECRETARIAS MUNICIPAIS DE SAÚDE (2020).

33. UNITED NATIONS (2020). 
homens e mulheres, visto que em meio a escalada de enfrentamento da COVID-19, a mulher foi compelida a guardar suas crises internas e lidar com as intemperes familiares, algumas consequência da quarentena decretada pelos governos internos, bem como com a avalanche emocional de seus familiares atordoados com o medo da contaminação do vírus, a mudança abrupta de suas rotinas, os afazeres domésticos sobrecarregados pelo convívio do núcleo familiar contínuo, as cobranças profissionais de um trabalho em home office que por vezes tem hora para começar, mas não tem perspectiva de terminar, entre outros elementos que compõem o isolamento social.

Embora a Constituição Federal traga a igualdade de todos perante a lei e outros diplomas infralegais abarquem o tema como uma espécie de reforço igualitário, na prática a sociedade brasileira ainda precisa evoluir muito para, de fato, repelir essa diferenciação de gênero: basta para isso analisar o conceito atual da crise para chegar à conclusão que no fim retorna-se ao status quo da mulher como responsável por tudo e todos, não lhe restando outra alternativa a não ser exercer o papel que sempre exerceu como matriarca que tudo deve suportar.

Conclui-se, então, que quando o assunto é desigualdade de gênero, esse cenário atual da pandemia destacou esse problema que remonta há séculos - não somente pela diferenciação do próprio gênero em si por suas características físicas e emocionais que socialmente buscou-se construir da mulher como um ser frágil, dotado da habilidades domésticas e emocional duvidoso, mas também por ser compelida a enfrentar uma realidade do medo coletivo, de excesso de trabalho que garante o seu sustento e dos seus, da sobrecarga de afazeres domésticos, dos problemas emocionais e suprimento de tarefas dos filhos, antes delegadas às escolas e a outros familiares, agora também isolados, da perda de seu emprego ou do companheiro/companheira que lhe gerou uma maior responsabilidade em prover seu lar, o afastamento de seu núcleo familiar, por vezes, em razão de ocupar cargo de linha de frente no combate ao novo vírus e que poderia gerar a sua contaminação e de seus familiares, a dor da perda de um ente querido para doença, a dor da violência, da fome, entre outros tantos vetores que contribuíram para acentuar uma desigualdade cada vez mais evidente.

\section{Referências bibliográficas}

MELERO AGUILAR, Noelia (2016): "Reivindicar la igualdad de mujeres y hombres en la sociedad: una aproximación al concepto de género". En Barataria. Revista Castellano-Manchega de Ciencias Sociales, No 11, pp. 73-83. Disponible en: $<$ https://revistabarataria.es/web/index.php/rb/article/view/152>. [Fecha de consulta: 15 de junio de 2020]. 
AZEVEDO, Júlio, ESTEVES, Diogo y SILVA, Franklyn (2020): "A vulnerabilidade das mulheres na pandemia. O que podemos aprender com a cruel pedagogia do vírus?". Disponible en: <https://www.jota.info/opiniao-e-analise/artigos/a-vulnerabilidade-das-mulheres-na-pandemia-13052020 $>$. [Fecha de consulta: 16 de junio de 2020].

BIANCHINI, Alice, BAZZO, Mariana y CHAKIAN, Silvia (2019): Crimes contra mulheres. (Salvador, Editora Juspodivm).

BRASIL. Ministério da Mulher, da Família e dos Direitos Humanos (2020): "Ligue 180". Disponible en: <https://www.gov.br/mdh/pt-br/navegue-por-temas/politicas-para-mulheres/ligue-180 >. [Fecha de consulta: 25 de junio de 2020].

BUTLER, Judith (2003): Problemas de gênero: feminismo e subversão da identidade. (Rio de Janeiro, Civilização Brasileira).

CECCARELLI, Paulo Roberto (2010): "Psicanálise, sexo e gênero: algumas reflexões". En Diversidades: Dimensões de Gênero e sexualidade. (Florianópolis, Ed. Mulheres). Disponible en: <http://www.ceccarelli.psc.br/admin/uploads/file/psicanalise-sexo-e-genero.pdf $>$. [Fecha de consulta: 25 de junio de 2020].

CHAKIAN, Silvia (2019): "Lei Maria da Penha: um basta à tolerância e banalização da violência contr a mulher". En Violência doméstica e familiar contra a mulher: um problema de toda a sociedade. (São Paulo, Paulinas).

CONSELHO NACIONAL DE SECRETARIAS MUNICIPAIS DE SAÚDE (2020): "Protagonismo feminino na saúde: mulheres são a maioria nos serviços e na gestão do SUS”. Disponible en: <https://www.conasems.org.br/o-protagonismo-feminino-na-saude-mulheres-sao-a-maioria-nos-servicos-e-na-gestao-do-sus/>. [Fecha de consulta: 26 de junio de 2020 ].

DIAS, Maria Berenice (2015): Manual de direito das famílias. (São Paulo, Editora Revista dos Tribunais).

FERRAZ, Carolina y LEITE, Glauber (2013): "A mulher nas relações familiares: a desconstrução de gêneros para a edificação da igualdade como garantia do desenvolvimento humano e social". En Manual dos direitos da mulher. (São Paulo, Saraiva).

FORUM BRASILEIRO DE SEGURANÇA PÚBLICA (2020): "Violência doméstica durante a pandemia de Covid-19 - ed. 2. 29 de maio de 2020". Disponible en: $<$ https://forumseguranca.org.br/wp-content/uploads/2020/o6/violencia-domestica-covid-19-edo2-v5.pdf $>$. [Fecha de consulta: 30 de junio de 2020].

GURGEL, Maria Aparecida (2019): "Mulher com deficiência - medidas adequadas para o seu desenvolvimento, avanço e empoderamento". En Diálogos aprofundados sobre os direitos das pessoas com deficiência. (São Paulo, RTM). 
G1 (2020): "OMS pede a governos que limitem acesso a bebidas alcoólicas durante pandemia de novo coronavírus”. Disponible en: <https://g1.globo.com/bemestar/ coronavirus/noticia/2020/o4/15/oms-pede-a-governos-que-limitem-acesso-abebidas-alcoolicas-durante-pandemia-de-novo-coronavirus.ghtml>. [Fecha de consulta: 15 de junio de 2020].

HERA: Health, Empowerment, Rights and Accountability (1998): "Women's Sexual and Reproductive Rights and Health". Disponible en: <https://31u5ac2nrwj6247cya153vw9-wpengine.netdna-ssl.com/wp-content/ uploads/1998/o1/HERA-Action-Sheets.pdf > . [Fecha de consulta: 18 de octubre de 2019].

HERNANDES, Elizabeth y VIEIRA, Luciana (2020): "A guerra tem rosto de mulher: trabalhadoras da saúde no enfrentamento à Covid-19". Disponible en: <http:// anesp.org.br/todas-as-noticias/2020/4/16/a-guerra-tem-rosto-de-mulhertrabalhadoras-da-sade-no-enfrentamento-covid-19>. [Fecha de consulta: 26 de junio de 2020].

IASC, Inter-Agency Standing Committee (2020): "Gender alert for COVID-19 outbreak: march 2020". Disponible en: <https://www.globalprotectioncluster.org/ wp-content/uploads/IASC-Interim-Guidance-on-COVID-19-Gender-Alert.pdf>. [Fecha de consulta: 14 de junio de 2020].

INSTITUTO MARIA DA PENHA (2020): "Nota Pública do Instituto Maria da Penha: Covid-19, Isolamento Social e Violência Doméstica e Familiar Contra as Mulhere". Disponible en: <https://www.institutomariadapenha.org.br/assets/downloads/nota_publica_abril_2020.pdf $>$. [Fecha de consulta: 30 de junio de 2020].

LAMAS, Marta (1994): "Cuerpo: diferencia sexual y género". En Debate Feminista, Vol. 10, pp. 3-31. Disponible en: <https://www.jstor.org/stable/42624175?read-no $\mathrm{w}=1$ \& refreqid=excelsior\%3Ad41ebb1cda763fcb7dc5 dobceaaf33e9\&seq=6\#page_ scan_tab_contents $>$. [Fecha de consulta: 30 de junio de 2020].

MELLO, Celso Antonio (2008): Conteúdo jurídico do princípio da igualdade (São Paulo, Malheiros).

PIOVESAN, Flávia (2008): "Igualdade de gênero na Constituição Federal: Os direitos civis e políticos das mulheres no Brasil”. En Constituição de 1988: o Brasil 20 anos depois. Os Alicerces da Redemocratização. Disponible en: <https://www12.senado.leg.br/publicacoes/estudos-legislativos/tipos-de-estudos/outras-publiccoes/ volume-i-constituicao-de-1988/principios-e-direitos-fundamentais-igualdadede-genero-na-constituicao-federal-os-direitos-civis-e-politicos-das-mulheresdo-brasil/view $>$. [Fecha de consulta: 14 de junio de 2020]. 
SHAPIRO, Judith (1981): "Anthropology and the study of gender". En Soundings: An Interdisciplinary Journal, Vol. 64, No 4, pp. 446-465. Disponible en: <https:// we.riseup.net/assets/562063/Shapiro\%2C+J.+\%281981\%29.+Anthropology+and+ the+study+of+gender.+Soundings\% $\%$ C $+446-465 . p d f>$. [Fecha de consulta: 20 de junio de 2020].

UNA-SUS (2020): "Organização Mundial de Saúde declara pandemia do novo Coronavírus". Disponible en: $<$ https://www.unasus.gov.br/noticia/organizacao-mundial-de-saude-declara-pandemia-de-coronavirus $>$. [Fecha de consulta: 14 de junio de 2020].

UNITED NATIONS (2020): "Policy Brief: The Impact of COVID-19 on Women". Disponible en: <https://www.un.org/sites/un2.un.org/files/policy_brief_on_covid_ impact_on_women_9_apr_2020_updated.pdf $>$. [Fecha de consulta: 30 de junio de 2020].

UNFPA BRASIL (2020): "Covid-19: Resumo Técnico Proteção da Saúde e dos Direitos Sexuais e Reprodutivos e Promoção da Igualdade de Gênero. Março 2020". Disponible en: <https://brazil.unfpa.org/sites/default/files/pub-pdf/covid19_olhar_genero.pdf $>$. [Fecha de consulta: 26 de junio de 2020].

WORLD HEALTH ORGANIZATION (2020): "Rolling updates on coronavirus disease (COVID-19)". Disponible en: <https://www.who.int/emergencies/diseases/ novel-coronavirus-2019/events-as-they-happen $>$. [Fecha de consulta: 14 de junio de 2020]. 